\title{
Managing feral pig threats on a tropical floodplain for fisheries values
}

\author{
Nathan Waltham ${ }^{1}$ and Jason Schaffer ${ }^{1}$ \\ ${ }^{1}$ James Cook University
}

January 26, 2021

\begin{abstract}
Efforts to protect and restore tropical wetlands impacted by feral pigs (Sus scrofa) in northern Australia have more recently included exclusion fences, an abatement response proposing fences improve wetland condition by protecting habitat for fish production and water quality. Here we tested: 1) whether the fish assemblage are similar in wetlands with and without fences; and 2) whether specific environmental processes influence fish composition differently between fenced and unfenced wetlands. Twenty-one floodplain and riverine wetlands in the Archer River catchment (Queensland) were surveyed during post-wet (JuneAugust) and late-dry season (November-December) in 2016, 2017 and 2018, using a fyke soaked overnight ( $\left.{ }^{\sim} 14-15 \mathrm{hrs}\right)$. A total of 6,353 fish representing twenty-six species from 15 families were captured. There were no multivariate differences in fish assemblages between seasons, years and for fenced and unfenced wetlands (PERMANOVA, Pseudo-F $<0.58, \mathrm{P}<0.68$ ). Late-dry season fish were considerably smaller compared to post-wet season: a strategy presumably to maximise rapid disposal following rain. At each wetland a calibrated Hydrolab was deployed (between 2-4 days, with 20min logging) in the epilimnion (0.2m), and revealed distinct diel water quality cycling of temperature, dissolved oxygen and $\mathrm{pH}$ (conductivity represented freshwater wetlands) which was more obvious in the late-dry season survey, because of extreme summer conditions. Water quality varied among wetlands, in terms of the daily amplitude, and extent of daily photosynthesis recovery, which highlights the need to consider local site conditions rather than applying general assumptions around water quality conditions for these types of wetlands examined here. Though many fish access (fenced and unfenced) wetlands during wet season connection, the seasonal effect of reduced water level conditions seems to be more over-improvised compared to whether fences are installed or not, as wetlands supported few, juvenile, or no fish species because they had dried completed regardless of whether fences were present or not.
\end{abstract}

\section{Hosted file}

Fish communities on tropical floodplain_Waltham.pdf available at https://authorea.com/ users/391897/articles/505890-managing-feral-pig-threats-on-a-tropical-floodplain-forfisheries-values

\section{Hosted file}

List of Figures.pdf available at https://authorea.com/users/391897/articles/505890-managingferal-pig-threats-on-a-tropical-floodplain-for-fisheries-values 